\title{
Efeito alelopático do extrato aquoso de folha e de fruto de leucena (Leucaena leucocephala Wit) sobre a germinação e crescimento de raiz da canafístula (Peltophorum dubium Spreng.)
}

\author{
Alelopathic effect of aqueous extracts of leucena (Leucaena \\ leucocephala Wit) leave and fruit on germination and root growth of \\ canafistula (Peltophorum dubium Spreng)
}

\author{
Luciani Márcia Scherer ${ }^{1}$, Valdir Zucareli ${ }^{1}$, Cristiane Aparecida Zucareli ${ }^{1}$, \\ Andréa Maria Teixeira Fortes ${ }^{2 *}$
}

Resumo

\begin{abstract}
Atualmente as plantas exóticas representam uma grande ameaça à biodiversidade pois, quando presente em ambientes que lhe são favoráveis, influenciam no desenvolvimento das plantas nativas, além de alterar o funcionamento natural daquele ambiente. Práticas de manejo erradas são um dos principais fatores que favorecem a invasão do ambiente pelas espécies exóticas. A leucena (Leucaena leucocephala Wit.) é uma espécie exótica que foi introduzida na recuperação da mata ciliar da Hidrelétrica de Itaipu, e pode possuir efeitos alelopáticos. Objetivou-se neste trabalho verificar a presença de efeitos alelopáticos do extrato aquoso de folha e fruto da leucena sobre a germinação e crescimento de raiz da canafístula (Peltophorum dubium Spreng), uma espécie nativa. Utilizou-se 12 tratamentos com 4 repetições. Os tratamentos utilizados foram: água, extratos com concentração de $20 \%, 40 \%, 60 \%, 80 \%$ e $100 \%$. Todas as sementes utilizadas foram previamente escarificadas mecanicamente. Realizou-se a avaliação das sementes germinadas diariamente e o comprimento das raízes no $3^{\circ} \mathrm{e} 7^{\circ}$ dia de experimento. Nas condições realizadas, o extrato de fruto apresentou potencial alelopático superior ao extrato de folhas. As raízes se mostraram sensíveis tanto ao extrato de fruto como de folha.
\end{abstract}

Palavras-chave: Alelopatia, sementes, leucena, canafístula

\begin{abstract}
Nowadays exotic plants represent a big threat to biodiversity because when they are present in favorable environments, they can influence the development of native plants, as well as they can change the natural functions of the environment. Wrong management practices are some of the main factors that support the environment invasions by exotic species. Leucena (Leucaena leucocephala Wit.) is an exotic species that takes part in Itaipu Dam recuperation riparian areas. Exotic species may have allelopathic effects. The objective of this study has been to verify allelopathic effects of aqueous extracts of leucena leaves and fruits upon germination and root growth of canafistula (Peltophorum dubium Spreng.), a native species. Twelve treatments with four replications have been used, divided in two stages, six treatments each. The utilized treatments were: water, $20 \%, 40 \%$, $60 \%, 80 \%$ and $100 \%$ extract. All the seeds were scared mechanically. The germinated seeds have been counted daily. The length of the roots has been evaluated at the third and seventh day of experiment. The fruit extract presented more allelopathic effects than the leaves extract. The roots were sensitive both to the fruits and leaves extract.
\end{abstract}

Key words: Allelopathy, seeds, leucaena, peltophorum

1 Alunos de Graduação da Unioeste

2 Professora adjunto da Universidade Estadual do Oeste do Paraná Rua Universitária, 2096 - Jardim Universitário 85 8140-110

Cascavel, PR, CEP 85814-110, email: amtfortes@unioeste.br, Telefone: (45) 2203239 ,

* Autor para correspondência.

Recebido para publicação 26/10/04 Aprovado em 15/04/05 


\section{Introdução}

As plantas exóticas representam atualmente um grande perigo para a flora mundial: a contaminação biológica. O processo de invasão de um ecossistema por uma planta exótica se dá quando qualquer espécie é introduzida nele, passando a se dispersar e a alterar esse ecossistema, afetando o funcionamento natural do mesmo e tirando o espaço das plantas nativas (ZILLER, 2001).

As primeiras transferências de espécies vegetais de uma região do planeta para outra tiveram a finalidade de suprir necessidades agrícolas, florestais e outras de uso direto. Com o tempo, mais da metade dessas espécies se tornaram invasoras, sendo que as plantas exóticas são hoje a segunda maior ameaça mundial à biodiversidade e só perdem para a destruição de hábitats (ZILLER, 2001).

Práticas erradas de manejo, como retirada de florestas, queimadas para preparo de terra, erosão e pastoreio excessivo contribuem para a perda da diversidade natural e fragilidade do meio a invasões. Outras características que potencializam a invasão são o crescimento rápido, maturação precoce, floração e frutificação mais longas, adaptação a áreas degradadas e liberação de toxinas capazes de impedir o crescimento de outras plantas nas imediações, processo denominado alelopatia (ZILLER, 2001).

A leucena (Leucaena leucocephala Wit.) é uma leguminosa exótica, originária do México, e é encontrada em toda a região tropical. A leucena mantêm-se verde na estação seca, perdendo somente os folíolos em secas muito prolongadas ou com geadas fortes. A planta apresenta um sistema radicular profundo, com poucas raízes laterais, que ocorrem em pequeno número próximas à superfície do solo. As folhas são bipinadas, com 15 a $20 \mathrm{~cm}$ de comprimento, apresentando quatro a dez pares de pinas, cada uma com cinco a vinte pares de folíolos em cada pina. Cada folíolo apresenta 7 a $15 \mathrm{~cm}$ de comprimento e 3 a $4 \mathrm{~mm}$ de largura. A inflorescência é globosa e solitária, sobre um pedúnculo com mais de $5 \mathrm{~cm}$ de comprimento, apresentando numerosas flores brancas. Essas inflorescências são de autopolinização que resultam em cachos de vagens, sendo estas estreitas e achatadas, com $20 \mathrm{~cm}$ de comprimento e $2 \mathrm{~cm}$ de largura, portam de 2 a 13 sementes, que apresentam cor marrom (SKERMAN, 1977). Essa planta apresenta características múltiplas de utilização, com destaque para o reflorestamento de áreas degradadas, alimentação animal e adubação verde (PRATES et al., 2000).

A leucena foi utilizada para a recomposição florestal do Refúgio Biológico de Santa Helena (RBSH), localizado no Sul do Brasil, oeste do Estado do Paraná, com latitudes sul entre $24^{\circ} 17^{\prime}$ e $24^{\circ} 21^{\prime}$ e longitudes W 54 21', ao Sul do Trópico de Capricórnio (latitude $23^{\circ} 27^{\prime}$ ') constituindo-se de duas ilhas dentro do reservatório de Itaipu, com uma área de 156,3 $\mathrm{km}^{2}$ (ZELAZOWSKI, 1990).

Com o início da colonização que ocorreu no Oeste do Paraná desde o final da década de 1960 até meados da de 70, a área do RBSH foi desbravada e passou a ser explorada por cultivos dominantes de soja, milho e trigo, sendo que o solo é bem desenvolvido e de alta fertilidade natural (ZELAZOWSKI, 1990). Com a formação do reservatório da Usina Hidrelétrica de ITAIPU, muitos dos moradores da área foram removidos, culminando assim com o início do reflorestamento realizado pela ITAIPU. Este trabalho empregou o uso de 46 espécies, sendo 27 nativas e 19 exóticas, dentre estas a Leucena (ZELAZOWSKI, 1990). Atualmente a leucena encontra-se amplamente disseminada nas margens do reservatório, invadindo plantações agrícolas e interferindo no seu desenvolvimento.

A alelopatia (do grego allelon, de cada outro + pathos, sofrimento), estuda a influência de uma espécie vegetal por substâncias produzidas por outra planta (RAVEN; EVERT; EICHHORN, 1996). No entanto, segundo Rice (1979), a alelopatia também pode ter efeitos benéficos para a planta, pois, os compostos químicos possuem efeito inibitório ou estimulante, o que depende da sua concentração no ambiente. 
As interferências alelopáticas são provocadas por geralmente mais de uma substância, denominadas de aleloquímicos ou produtos secundários e que são encontradas distribuídas em concentrações variadas nas diferentes partes da planta, folhas e raízes, e também, durante o seu ciclo de vida (periodicidade). Quando essas substâncias são liberadas em quantidades suficientes, causam efeitos alelopáticos que podem ser observados na germinação, no crescimento e/ou no desenvolvimento de plantas já estabelecidas e, ainda no desenvolvimento de microorganismos (CARVALHO, 1993).

Estudos sobre os efeitos alelopáticos de algumas gramíneas e leguminosas foram realizados por Medeiros, Castro e Lucchesi, (1990), por meio dos quais verificou-se que a aveia (Avena sativa) por exemplo pode ser utilizada como cultura de cobertura com propriedades alelopáticas propiciando a redução de plantas daninhas.

Nas plantas, as substâncias alelopáticas desempenham as mais diversas funções, sendo responsáveis pela prevenção da decomposição das sementes, interferem na sua dormência e também na das gemas e influenciam as relações com outras plantas, com microrganismos, com insetos e até com animais superiores, incluindo o homem (DURIGAN; ALMEIDA, 1993).

Segundo funcionários do RBSH, algumas espécies apresentam um baixo índice de germinação no viveiro local, como por exemplo, a canafístula (Peltophorum dubium Spreng.). A canafístula é encontrada nos Estados da Bahia, Rio de Janeiro, Minas Gerais, Goiás e Mato Grosso do Sul até o Paraná. Possui folhas compostas bipinadas, com 12 20 pares de pinas e 20-30 pares de folíolos por pina. Ocorre em solos argilosos e úmidos de beira de rios e se caracteriza por ser uma planta decídua de abundante e ampla dispersão principalmente em áreas próximas a rios. Floresce durante os meses de dezembro-fevereiro. A maturação dos frutos ocorre nos meses de março-abril, entretanto suas vagens permanecem viáveis na árvore durante muitos meses (LORENZI, 1992).
O presente trabalho objetivou estudar o efeito alelopático do extrato aquoso de folha e de fruto de leucena em diversas concentrações sobre a germinação e crescimento de raiz da Canafístula.

\section{Material e Métodos}

O experimento foi desenvolvido no laboratório da UNIOESTE- Extensão Santa Helena- Pr, em duas etapas, com intervalo de 10 dias, sendo a primeira com o extrato aquoso de folha de leucena e a segunda com extrato de fruto.

As sementes da canafístula foram coletadas manualmente pelos funcionário do RBSH durante o mês de abril de 2004 e acondicionadas em sacos de papel, sob refrigeração. Ao início de cada etapa, as sementes foram escarificadas com lixa $\mathrm{n}^{\circ} 80$ no lado oposto ao embrião até atingir o endosperma. Posteriormente, realizou-se tríplice lavagem em água corrente, em seguida as sementes foram colocadas por 10 minutos em solução de hipoclorito de sódio a 10\%.

Para a $1^{\text {a }}$ etapa, utilizou-se o extrato aquoso das folhas de leucena, onde os folíolos foram colhidos minutos antes da montagem do experimento. Realizou-se a trituração em liquidificador de 200 gramas de folíolos, juntamente com 1 litro de água destilada.

Para a $2^{\mathrm{a}}$ etapa, utilizou-se o extrato de fruto de Leucena, sendo estes, colhidos maduros momentos antes da montagem do experimento, em seguida, triturou-se 200 gramas de frutos, em um litro de água destilada.

Os extratos obtidos foram coados, em seguida fez-se às diluições para os tratamentos a seguir:

$1^{\text {a }}$ ETAPA: extrato aquoso de folha de leucena. T1: $\mathrm{H}_{2} \mathrm{O}$; T2: Extrato aquoso de folha de leucena à $20 \%$; T3: Extrato aquoso de folha de leucena à 40\%; T4: Extrato aquoso de folha de leucena à $60 \%$; T5 Extrato aquoso de folha de leucena à $80 \%$; T6 Extrato aquoso de folha de leucena à 100\%.

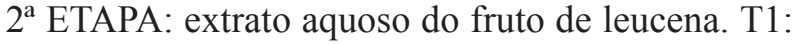
$\mathrm{H}_{2} \mathrm{O}$; T2: Extrato aquoso de fruto de leucena à $20 \%$; 
T3: Extrato aquoso de fruto de leucena à $40 \%$; T4: Extrato aquoso de fruto de leucena à $60 \%$; T5: Extrato aquoso de fruto de leucena à $80 \%$; T6: Extrato aquoso de fruto de leucena à 100\%.

Depois de obtidos os extratos, utilizou-se papel germitest previamente autoclavado por 20 minutos a $120^{\circ} \mathrm{C}$. O papel germitest foi pesado e acrescentouse 2,5 o seu peso com os extratos. Foram utilizados 4 repetições com 50 sementes para cada concentração.

As sementes foram colocadas em uma câmara de germinação com temperatura interna constante a $25^{\circ} \mathrm{C}+-2^{0}$ com fotoperíodo de doze horas (USBERTI; FELIPE, 1980). A assepsia da câmara de germinação foi realizada periodicamente com solução desinfetante (Lysoform 10\%) e também com solução antifúngica (Candistatin 10\%).

O delineamento experimental empregado para cada uma das etapas foi inteiramente casualizado, com 6 tratamentos e 4 repetições, com 50 sementes por parcela.

A contagem da germinação teve início no $3^{0}$ dia após a semeadura, seguindo-se de leituras diárias até o $7^{\circ}$ dia e, considerando-se como semente germinada aquela que apresentar radícula com aproximadamente $2 \mathrm{~mm}$ de comprimento (HADAS, 1976).

Para avaliar o crescimento da raiz, realizou-se a medida da mesma ao $3^{\circ}$ e $7^{\circ}$ dia após o início do experimento. Os dados obtidos foram submetidos à análise de variância (teste F) e as médias comparadas pelo teste de Tukey a 5\% de probabilidade.

Para porcentagem de germinação, os dados obtidos foram submetidos à análise de variância (teste F), utilizando-se a transformação arco seno da raiz quadrada da porcentagem, sendo as médias comparadas pelo teste de Tukey a 5\% de probabilidade (PIMENTEL-GOMES, 1990). Além disso, foram realizadas observações quanto ao tempo médio de germinação $(\mathrm{t})$ e à velocidade média de germinação (v), calculados, segundo Labouriau
(1983): $\mathrm{t}=\bullet$ ni.ti $($ dias $) / \cdot n$ total e $\mathrm{v}=1 / \mathrm{t}($ sementes $/$ dia $)$; onde: $\mathrm{t}=$ tempo médio de germinação (dias); $\mathrm{n}=$ número de sementes germinadas num intervalo de tempo; $\mathrm{ti}=$ intervalo de tempo; $\mathrm{n}$ total $=$ número total de sementes germinadas; $v=$ velocidade média de germinação.

\section{Resultados e Discussão}

Analisando as Tabelas 1 e 2, observaram-se diferenças entre os potenciais alelopáticos da parte aérea e dos frutos da leucena, pois os parâmetros porcentagem de sementes germinadas e velocidade média de germinação apresentam diferenças estatísticas quando comparadas as duas etapas, contrariando Alves (1992), que cita a parte aérea das plantas como a mais importante fonte de substâncias alelopáticas. Esta comparação só é possível porque os Coeficientes de Variação (CV) são muito próximos (etapa $1-8,61$ e etapa $2-8,29$ ).

Deste modo, observou-se que para o extrato de folha de leucena não houve diferença significativa entre os parâmetros tempo médio e velocidade média de germinação. Apenas o parâmetro porcentagem de sementes germinadas apresentou diferença no tratamento 6 (extrato de folha de leucena a 100\%), que demonstrou uma porcentagem menor de sementes germinadas (19\%) em relação aos outros tratamentos. (Tabela 1).

Tabela. 1. Porcentagem (\%SG), tempo médio (TMG), velocidade média (VMG) de germinação e comprimento de raiz ao $3^{\circ}$ e $7^{\circ}$ dia de experimento, de sementes de canafistula (Peltophorum dubium Spreng.) submetidas aos tratamentos com extratos aquosos de folha de leucena.

\begin{tabular}{lccccc}
\hline \multicolumn{1}{c}{ Tratamentos } & \% SG & TMG & VMG & C. R. 3 dia & C. R. 7 dia \\
\hline T1 - Água & 93,5 a & 0,188 a & 5,782 a & 1,04 a & $5,95 \mathrm{a}$ \\
T2 - Extrato folha 20\% & 95,0 a & 0,246 a & $4,112 \mathrm{a}$ & $0,96 \mathrm{ab}$ & $5,95 \mathrm{a}$ \\
T3 - Extrato folha 40\% & $95,5 \mathrm{a}$ & 0,219 a & $4,740 \mathrm{a}$ & $0,93 \mathrm{ab}$ & $5,46 \mathrm{a}$ \\
T4 - Extrato Folha 60\% & $95,5 \mathrm{a}$ & 0,270 a & $4,006 \mathrm{a}$ & $0,95 \mathrm{ab}$ & $5,15 \mathrm{a}$ \\
T5 - Extrato folha 80\% & $94,5 \mathrm{a}$ & 0,206 a & $4,956 \mathrm{a}$ & $0,76 \mathrm{ab}$ & $5,27 \mathrm{a}$ \\
T6- Extrato folha 100\% & $19,0 \mathrm{~b}$ & 0,317 a & $3,583 \mathrm{a}$ & $0,44 \mathrm{~b}$ & $2,02 \mathrm{~b}$ \\
\hline C.V & 8,61 & 31,8 & 29,8 & 28,2 & 8,5 \\
\hline
\end{tabular}

Médias seguidas de mesma letra não diferem significativamente entre si, pelo teste Tukey, no nível de $5 \%$ de probabilidade. 
Quanto ao comprimento de raiz, observou-se que no $3^{\circ}$ dia após a montagem do experimento, a análise estatística demonstra que apenas o T1 difere do T6. No $7^{\circ}$ dia, os tratamentos T1, T2, T3, T4, e T5 não apresentaram diferenças estatísticas, no entanto, o T6 (extrato aquoso de folha leucena a 100\%) apresentou o menor comprimento de raiz (Tabela 1).

Estes resultados concordam com o trabalho realizado por Souza Filho et al. (1997), que citam que independentemente da fonte do extrato, as raízes geralmente se apresentam mais sensíveis.

Em relação ao fruto, a leucena apresentou efeitos alelopáticos mais evidentes nos parâmetros de porcentagem de sementes germinadas e velocidade média de germinação (Tabela 2).

Tabela 2. Porcentagem (\%SG), tempo médio (TMG), velocidade média de germinação (VMG) e comprimento de raiz ao $3^{\circ}$ e $7^{\circ}$ dia de experimento, de sementes de canafistula (Peltophorum dubium Spreng.) submetidas aos tratamentos com extratos aquosos de fruto de leucena.

\begin{tabular}{lccccc}
\hline Tratamentos & \% S.G. & T.M.G. & V.M.G. & C. R. 3 dia & C. R. 7 dia \\
\hline T1 - água & $91,5 \mathrm{a}$ & $0,174 \mathrm{a}$ & $5,815 \mathrm{a}$ & $2,1 \mathrm{a}$ & $5,4 \mathrm{a}$ \\
T2 - Extrato fruto 20\% & $84 \mathrm{a}$ & $0,253 \mathrm{a}$ & $4,724 \mathrm{ab}$ & $1,1 \mathrm{~b}$ & $1,8 \mathrm{bc}$ \\
T3 - Extrato fruto 40\% & $82 \mathrm{a}$ & $0,352 \mathrm{a}$ & $3,82 \mathrm{ab}$ & $1,2 \mathrm{~b}$ & $2,3 \mathrm{~b}$ \\
T4 - Extrato fruto 60\% & $52,5 \mathrm{~b}$ & $0,329 \mathrm{a}$ & $2,938 \mathrm{~b}$ & $0,7 \mathrm{c}$ & $1,7 \mathrm{bc}$ \\
T5 - Extrato fruto 80\% & $35,5 \mathrm{c}$ & $0,32 \mathrm{a}$ & $3,437 \mathrm{~b}$ & $0,5 \mathrm{c}$ & $1,5 \mathrm{c}$ \\
T6 - Extrato fruto 100\% & $19,5 \mathrm{~d}$ & $0,359 \mathrm{a}$ & $3,26 \mathrm{~b}$ & $0,4 \mathrm{c}$ & $0,4 \mathrm{~d}$ \\
\hline C.V & 8,29 & 32,23 & 25,72 & 13,51 & 15,43 \\
\hline
\end{tabular}

Médias seguidas de mesma letra não diferem significativamente entre si, pelo teste Tukey, ao nível de $5 \%$ de probabilidade

Conforme a Tabela 2, o tempo médio de germinação não apresentou variação estatística. Em relação à porcentagem de sementes germinadas, observou-se que quanto maior a concentração do extrato, menor a porcentagem de germinação, no entanto, estatisticamente T2 e T3 não diferiram de T1.

Em relação ao comprimento da raiz, tanto no $3^{\circ}$ quanto no $7^{\circ}$ dia, todos os tratamentos diferiram da testemunha, no entanto, no $7^{\circ}$ dia T2 e T4 não diferiram entre si e ambos foram iguais a $\mathrm{T} 3 \mathrm{e} \mathrm{T} 5$. $\mathrm{O}$ tratamento $\mathrm{T} 6$ apresentou-se diferenciado do tratamento testemunha. De acordo com Jacobi e
Ferreira (1991) a inibição do desenvolvimento após a germinação sob ponto de vista ecológico é uma forma de seleção que elimina a descendência.

Estes resultados também se apresentam de acordo com o trabalho realizado por Souza Filho, Rodrigues e Rodrigues (1997), que citam o extrato aquoso de fruto de Leucena com potencial inibitório superior ao da parte aérea.

Segundo ainda Souza Filho, Rodrigues e Rodrigues (1997), a superioridade do extrato de fruto de leucena em inibir a germinação e o crescimento da raiz, está, provavelmente, associado à distribuição de um aleloquímico na planta, denominado mimosina, que é um aminoácido não-protéico que ocorre nas folhas e sementes de espécies como Leucaena e Mimosa. Em seus estudos, Smith e Fowden (1966) observaram que a mimosina inibiu o crescimento de seedlings de feijão-mungo (Phaseolus vulgaris). Kuo, Chou e Hu (1982) verificaram que a mimosina presente na leucena inibiu o crescimento da radícula de alface (Lactuca sativa).

Pereira e Alcântara (1993) mostraram que a mimosina está presente em níveis mais elevados nas sementes (12,1\% na matéria seca), enquanto nas folhas jovens e nas maduras, a mimosina é encontrada nas concentrações de 4 a $2 \%$ respectivamente, na matéria seca, o que atribui aos frutos as maiores interferências em processos fisiológicos, como: germinação e desenvolvimento de radícula.

Os resultados também estão de acordo com Friedman e Waller (1983), que mencionam que os aminoácidos não-protéicos, são encontrados principalmente nas sementes, podendo ocorrer em concentrações extremamente altas.

\section{Conclusões}

$\mathrm{Na}$ leucena o extrato de fruto possui potencial alelopático em qualquer concentração, sendo que quanto maior a concentração, maior o efeito. Já o extrato de folha só apresentou efeito alelopático em concentração de $100 \%$ em extrato aquoso. 


\section{Agradecimentos}

À Prefeitura Municipal de Santa Helena-PR, pelo apoio financeiro.

\section{Referências}

ALVES, P. L. C. A. Interações alelopáticas entre plantas daninhas e hortaliças. In: SIMPÓSIO NACIONAL SOBRE MANEJO INTEGRADO DE PLANTAS DANINHAS EM HORTALIÇAS, 1992, Botucatu. Anais...Botucatu, 1992. p. 19-43

CARVALHO, S. C. I. Caracterização dos efeitos alelopáticos de Brachiaria brizantha ev. Marundu no estabelecimento das plantas de Stylosanthes guianensis var. vulgaris ev. Bandeirantes. 1993. 72 p Dissertação (Mestrado em Zootecnia)-Universidade Federal de Viçosa, Viçosa, 1993.

DURIGAN, J. C; ALMEIDA, F. S. Noções sobre alelopatia. Jaboticabal: UNESP/FUNEP, 1993. 28 p.

FRIEDMAN, J.; WALLER, G. R. Seeds as allelopathic agents. Journal of Chemical Ecology, New York, v. 9, n. 8,p. 1107-1117. 1983.

HADAS, A. Water uptake and germination of leguminous seeds under changing external water potential in osmotic solution. Journal of Experimental Botany, Oxford, v. 27, n. 98, p. $480-489,1976$.

JACOBI, U. S.; FERREIRA, A. G. Efeitos alelopáticos de Mimosa bimunocrata (DC) OK sobre espécies cultivadas. Pesquisa Agropecuária Brasileira, Brasília, v. 26,n. 7, p. 935-943, 1991.

KUO, Y. L.; CHOU, C. H.; HU, T. W. Allelopathic potencial of Leucaena leucocephala. Leucaena Research Report, Taipei, v. 3, p. 65-70, 1982.

LABOURIAU, L. G. A germinação de sementes. Washington: Organização dos Estados Americanos, 1983. 174p.

LORENZI, H. Árvores Brasileiras: manual de identificação e cultivo de plantas arbóreas do Brasil. 2. ed. Nova Odessa: Plantarum, 1992.368 p. v. 2.
MEDEIROS, A. R. M.; CASTRO, L.A.S.; LUCCHESI, A.A.. Efeitos alelopáticos de algumas leguminosas e gramíneas sobre a flora invasora. Anais da ESALQ, Piracicaba, v. 47, p. 1-10,1990.

PIMENTEL-GOMES, F. Curso de estatística experimental. São Paulo: Nobel, 1990.

PEREIRA, A. F.; ALCÂNTARA, P. B. Fatores antinutricionais com Leucaena leucocephala Wit. In: SIMPÓSIO SOBRE USOS MÚLTIPLOS DE LEGUMINOSAS ARBUSTIVASE ARBÓREAS, 1993, Nova Odessa. Anais...Nova Odessa: FAPESP, 1993. p. 183-202.

PRATES, H. T.; PAES, J. M. V.; PIRES, N. M.; PEREIRA FILHO, I. A.; MAGALHÃES, P. C. Efeito do extrato aquoso de Leucena na germinação e no desenvolvimento do milho. Pesquisa Agropecuária Brasileira, Brasília, v. 35, n. 5, p. 909-914, 2000.

RAVEN, P. H.; EVERT, R. F.; EICHHORN, S. E. Biologia Vegetal. 5. ed. Rio de Janeiro: Guanabara Koogan, 1996. $728 \mathrm{p}$.

RICE, E. L. Allelopathy: an update. Botanical Review, Bronx, v. 45, n. 1, p. 15-109, 1979.

SKERMAN, P. J. Tropical forage legumes. Rome: FAQ, $1977.609 \mathrm{p}$.

SMITH, J. K.; FOWDEN, L. A study of mimosine toxicity in plants. Journal of Experimental Botany, Oxford, v. 17, p. 750-761, 1966.

SOUZA FILHO, A. P. S.; RODRIGUES, L. R. A.; RODRIGUES, T. J. D. Efeitos do potencial alelopático de três leguminosas forrageiras sobre três invasoras de pastagens. Pesquisa Agropecuária Brasileira, Brasília, v. 32, n. 2, p. 165-170, 1997.

USBERTI, R., FELIPE, G. M. Viabilidade de sementes de Citrus limonia Osb. Com baixo teor de umidade, armazenada em diferentes temperaturas. Pesquisa Agropecuária Brasileira, Brasília, v. 15, n. 4, p. 393-397, 1980.

ZELAZOWSKI, V. H. Revegetalização do Refúgio Biológico de Santa Helena-Pr, Itaipu Binacional. Santa Helena, Prefeitura Municipal, 1990.

ZILLER, S. R. Opinião. Revista Ciência Hoje, São Paulo, v. 30, n. 178 , p. $78,2001$. 